\title{
SHORT COMMUNICATION \\ PSYCHOSOCIAL IMPACTS AMONG ADOLESCENTS DISENGAGED FROM COLOMBIAN ILLEGAL ARMED GROUPS AND CHALLENGES TO THEIR ATTENTION
}

\author{
Jana Hudcovská, Kräuff Schwanhaeuser \\ Department of Public Health, Faculty of Medicine, Masaryk University, Brno, Czech Republic
}

\section{SUMMARY}

Objectives: Our study focused on the impacts on health among adolescents who became members of illegal armed groups in Colombia and their attention within the specialized government programme as seen by the professionals who work directly with them. Previous research indicates that those victims of armed violence are usually highly affected on their emotional and social health, but with appropriate and timely support more serious mental health problems can be prevented. Therefore, the care provided to them should be based on broader and holistic approaches.

Methods: This cross-sectional study used the qualitative method based on semi-structured interviews with 42 professionals, and internal reports on the health condition of 165 adolescents, $57(34.5 \%)$ females and $108(65.5 \%)$ males, as a secondary source of information. All information was anonymous and confidential.

Results: The interviews with professionals and their reports demonstrated that about a half of the 165 adolescents, 35 of $57(61.4 \%)$ females and 48 of $108(44.4 \%)$ males, suffered from serious symptoms requiring therapeutic and psychiatric attention. About $20 \%$ of the adolescents presented clinically important post-traumatic stress symptoms, $27 \%$ admitted sexual abuse and $29 \%$ psychoactive substance abuse. The professionals stressed various obstacles to the attention of these multiple impacts related both to the administrative and institutional issues and the particular characteristics of this population.

Conclusions: Our findings show the complexity of the psychosocial impacts among adolescent victims of the Colombian armed conflict and their attention. Highly trained professionals and alternative strategies including active listening, observation and art therapy activities seem to be vital for an effective care. The lessons learned from the Colombian reintegration programme serve as important inputs to be considered when attending children and adolescents from conflict-stricken areas also in other contexts.

Key words: child soldiers, reintegration programme, psychosocial attention, mental health, Colombia

Address for correspondence: J. Hudcovská, Department of Public Health, Faculty of Medicine, Masaryk University, University Campus A21-321, Kamenice 5, 62500 Brno, Czech Republic. E-mail: jana.hudcovska@mail.muni.cz

https://doi.org/10.21101/cejph.a6053

\section{INTRODUCTION}

Armed conflicts have immeasurable impacts on the whole populations and particularly on their most vulnerable segments, such as children and adolescents. They face multiple rights violations, and in case of being recruited by an armed group, usually a combination of different traumatic experiences that leave them with multiple consequences on their physical, mental and social health (1-3). On the other hand, these youth frequently show high levels of resilience and agency (4) that with appropriate support may help them recover without requiring more profound interventions $(5$, $6)$. Therefore, the narrow trauma-focused attitudes have been in great part overcome (7) and replaced by more holistic psychosocial focuses (6) aimed to prevent serious mental health problems and promote the well-being of these armed conflict victims.

In Colombia, from 1960 to 2016, nearly 17 thousand children were recruited by different local illegal armed groups (8). Their rights are restored within the specialized programme of the govern- ment institution called the Colombian Institute of Family Welfare (Spanish acronym ICBF). It contracts with external organizations to run the programme through institutional and family-based models of attention targeting the areas of labour and social reinsertion, and mental health support. The adolescents count on a multidisciplinary team of professionals who provide psychosocial accompaniment (9), referring the adolescents with more serious symptoms to therapeutic and clinical treatments with external institutions.

The principal objective of this study was to contribute to the discussion on the effective attention for adolescents affected by armed violence. Recently, the refugee and migrant crisis in Europe has raised many questions about how to attend and assure inclusion of more than a million migrant children (10). This research focused on psychosocial impacts among Colombian former child soldiers and on the obstacles to their attention can bring an important insight on the complexity of the topic and important lessons for professionals who attend direct and indirect victims of armed conflicts in other contexts. 


\section{MATERIALS AND METHODS}

This cross-sectional study used the qualitative method based on semi-structured interviews with 42 professionals $(65.6 \%$ of the targeted population) who were directly in charge of the adolescents in the specialized programme. The participants $(71.4 \%$ of females, $28.6 \%$ of males) were selected through non-probabilistic purposive sampling and on the criteria of voluntary participation, professional experience within the specialized programme and time availability. Their work experience ranged from one month to ten years within the programme, $31 \%$ of them were psychologists, $21.4 \%$ were social workers, and the rest included coordinators of the institutions, pedagogues, educators, nutritionists, and family ombudsman. The research was carried out in five Colombian towns (Bogotá, Medellín, Cali, Villavicencio, Armenia) in six different organizations, five family ombudsman offices and four regional ICBF centres from September 2018 to January 2019. This investigation was approved by the Department of Rights Restoration of the ICBF headquarters in Bogotá (S-2018-5010930101, 28 August 2018).

With two exceptions, informal talks were carried out with all professionals before the formal interviews. All participants were informed about the objectives and procedures of the study and signed the informed consent. The first author conducted all interviews in Spanish; they took from 20 minutes do 1 hour 50 minutes (mean time of about 50 minutes). All interviews were performed in a private place, tape-recorded, subsequently transcribed and the transcriptions were revised by a native Colombian sociology student. The data were analysed using the inductive content analysis (11) that on the basis of meaning units led to the identification of sub-themes and principal themes.

In addition to the interviews with professionals, secondary sources in form of internal reports of those professionals on the health condition and attention received by 165 adolescents (about $60 \%$ of those actually attending the specialized programme) were revised. Anonymity and confidentiality of all the information and data was assured.

\section{RESULTS}

The information on psychosocial conditions of the adolescents was not systematized within the ICBF specialized programme, thus the following summary data provides only a general orientation. According to the 165 internal reports $(34.5 \%$ of females, $65.5 \%$ of males, average age $16.87 \pm 0.24$ years), 44 adolescents ( $82 \%$ of females, $18 \%$ of males) admitted being sexually abused during their childhood, in the armed group or in both situations. In 47 cases ( $21.3 \%$ of females, $78.7 \%$ of males), a previous or actual psychoactive substance consumption was detected. About $20 \%$ of adolescents suffered from clinically important posttraumatic stress symptoms, were medicated or waiting for the psychiatric attention. Another more than $7 \%$ of the adolescents were medicated due to other disorders (such as bipolar disorder) or a suicidal intent, and nearly $13 \%$ of adolescents were treated for the substance-induced anxiety. Overall, about $50 \%$ of all adolescents, 35 females (61.4\%) and 48 males (44.4\%), presented serious symptoms that required more specialized psychiatric and/ or psychological attention. In this sense, the girls were more af- fected than the boys (chi-squared test, $\mathrm{p}=0.038$ ). Apart from these clinically significant symptoms, other important issues included behavioural problems with tendency to aggression, withdrawn and distant attitudes, mild to moderate cognitive impairments, low self-esteem, feelings of guilt and emotional voids related to the biologic family.

Various challenges to the attention of these multiple psychosocial impacts among adolescents were identified and divided into two broader categories. The first one is constituted by the institutional and administrative system itself. Adolescents who needed external treatments depended on the often limited availability of such services. Since they were from different parts of Colombia, the problem with "portability" related to the healthcare insurance hindered even more their access to those services. The quality of care was also put in doubt since the majority of the external professionals lacked specializations on trauma and armed conflict victims, and thus may not understand the emotional complexities in such adolescents. Within the organizations, particularly the administrative burden and the frequent rotation of professionals prevented them from providing a real psychosocial accompaniment to the adolescents. The professionals also called for including a trained clinical psychologist, an expert on psychoactive substance abuse and an anthropologist due to the indigenous adolescents in their teams. The second category of challenges refers to the characteristics of the adolescents, who are frequently too reluctant to share their feelings, do not want to confront their hidden pains, and present themselves as not having any problems. Many of them see a consultation with a psychologist as a sign of weakness, arguing they are not crazy. According to the professionals, these facts often impeded the possibility to talk directly about past experiences.

\section{DISCUSSION}

As the results showed, to exactly quantify the mental health and/or psychosocial problems of these victims of the Colombian armed conflict would be misleading. Their emotional conditions are very unpredictable, they often pretend to be "fine", hide their real feelings and experience emotional fluctuations during the reintegration process. These adolescents were highly emotionally affected in several ways; the data on prevalence of the post-traumatic stress disorder and other clinically relevant mental health impacts did not differ from results in other contexts $(3,12)$. Moreover, the victims of sexual abuse constituted a significant proportion among these adolescents and required particularly sensitive attitudes and focused therapeutic care. Another relevant and increasing issue evidenced within the programme was the psychoactive substance abuse. Nevertheless, also those adolescents who do not present symptoms requiring more clinical attention need guidance, orientation and help to strengthen their skills, heal their emotional wounds and be able to function properly in social environments often different to those they were accustomed to.

All the professionals who work with these adolescents should be specifically trained and aware of the distinctive characteristics of this population. The often seen tendency to diagnose all those adolescents with post-traumatic stress and medicate them should be avoided. Moreover, other multiple obstacles to provide timely actions focused on prevention, rather than on 
crisis attention, such are the failures of the general health system and administrative procedures within the programme, make the attention of the adolescents particularly intricate. Therefore, the professionals need to search for alternative strategies based on active listening, observation and leisure, art, symbolic group and small group activities. To build confidence with the adolescents is the indispensable step for the professionals so that they can target their deep emotional scars and prevent occurrence of more serious mental health problems. An increasing body of literature has documented psychosocial interventions for youth affected by armed conflicts in different contexts, but in great part presenting rather short-term actions with mixed results $(13,14)$. The experiences from the Colombian reintegration programme for children and adolescents based on more systematic and long-term attention thus bring a broader insight into the complexity of such attention and related processes.

\section{CONCLUSIONS}

Our results provide a valuable contribution to the efforts of providing the young armed conflict victims with effective care and support that would ensure their adequate psychosocial condition and well-being. In European countries these lessons learned can serve as important inputs to be considered when designing programmes of attention for migrant children and adolescents.

\section{Acknowledgements}

The authors thank to the Colombian Institute of Family Welfare to support this study and allow the access to the specialized programme.

\section{Conflict of Interests}

None declared

\section{REFERENCES}

1. Graça Machel. Impact of armed conflict on children [Internet]. United Nations; 1996 [cited 2019 Jun 25]. Available from: https://undocs. org/A/51/306.

2. Colombian Institute of Family Welfare, International Organization for Migration, United Nations International Children's Emergency Fund. The armed conflict impact on the psychosocial condition of children and adolescents. Bogotá: Colombian Institute of Family Welfare; 2014. (In Spanish.)

3. Schauer E, Elbert T. The psychological impact of child soldiering. In Martz E, editor. Trauma rehabilitation after war and conflict: community and individual perspectives. New York: Springer; 2010. p. 311-60.

4. Masten AS. Global perspectives on resilience in children and youth. Child Dev. 2014 Jan-Feb;85(1):6-20.

5. Betancourt T, Borisova I, Rubin-Smith J, Gingerich T, Williams T, Angew-Blais J. Psychosocial adjustment and social reintegration of children associated with armed forces and armed groups: the state of the field and future directions [Internet]. Austin (TX): Psychology Beyond Borders; 2008 [cited 2019 May 29]. Available from: http://psychologybeyondborders.org/wp-content/uploads/2013/08/RPCGA-CAAFAGREPORT-FINAL-JULY-2008.pdf.

6. Derluyn I, Vindevogel S, De Haene L. Toward a relational understanding of the reintegration and rehabilitation processes of former child soldiers. J Aggress Maltreat Trauma. 2013;22(8):869-86.

7. Miller KE, Rasmussen A. War exposure, daily stressors, and mental health in conflict and post-conflict settings: bridging the divide between traumafocused and psychosocial frameworks. Soc Sci Med. 2010 Jan;70(1):7-16.

8. National Centre for Historical Memory. A war without age. National report on the recruitment and use of children and adolescents in the Colombian armed conflict. Bogotá: CNMH; 2017. (In Spanish.)

9. Colombian Institute of Family Welfare. Technical guidelines on the psychosocial accompaniment strategy for the restoration of rights and contribution to the integral reparation of children and adolescent victims of the armed conflict [Internet]. Bogotá: ICBF; 2016 [cited 2019 Jun 5]. Available from: https://www.icbf.gov.co/sites/default/files/procesos/ 1m10.p_lineamiento_tecnico_acompanamiento_psicosocial_a_ninos ninas_y_adolescentes_victimas_de_conflicto_armado_v1.pdf. (In Spanish.)

10. Health of refugee and migrant children. Technical guidance on refugee and migrant health. Copenhagen: WHO Regional Office for Europe; 2018.

11. Elo S, Kyngäs H. The qualitative content analysis process. J Adv Nurs. 2008 Apr;62(1):107-15.

12. Dimitry L. A systematic review on the mental health of children and adolescents in areas of armed conflict in the Middle East. Child Care Health Dev. 2012 Mar;38(2):153-61.

13. Jordans MJD, Pigott H, Tol WA. Interventions for children affected by armed conflict: a systematic review of mental health and psychosocial support in low- and middle-income countries. Curr Psychiatry Rep. 2016;18(1):9. doi:10.1007/s11920-015-0648-z.

14. Brown FL, de Graaff AM, Annan J, Betancourt TS. Annual research review: breaking cycles of violence - a systematic review and common practice elements analysis of psychosocial interventions for children and youth affected by armed conflict. J Child Psychol Psychiatry. 2017 Apr;58(4):507-24. 